Direct Predictive Speed Control of Salient PMSM Drives in Constant Torque and Constant Power Regimes for Electric Vehicles Applications

Vol. 39(2), pp. 127-143, Dec. 2020

ISSN 1821-536X (print)

ISSN 2619-8789 (electronic)
Tanzania Journal of Engineering and Technology Copyright $\odot 2020$ College of Engineering and Technology, University of Dar es Salaam

Full Length Research Paper

\title{
Direct Predictive Speed Control of Salient PMSM Drives in Constant Torque and Constant Power Regimes for Electric Vehicles Applications
}

\author{
Francis Mwasilu
}

Department of Electrical Engineering, University of Dar es Salaam, Tanzania

*Corresponding author: fmwasilu@ieee.org; fmwasilu@udsm.ac.tz

\begin{abstract}
A direct speed control of salient permanent magnet synchronous motor (PMSM) drives in constant torque and constant power regimes for electric vehicles applications is presented. The proposed speed control scheme is derived from model predictive control approach where both rotor speed and stator current are formulated in a single objective function that is periodically computed to attain the PMSM drive optimum switching states. The dynamic model of the PMSM intrinsically encompasses the unknown disturbance, which should be rejected for high-performance speed control especially in transient conditions. Consequently, the extended modified augmented state Kalman filter (ASKF) is incorporated in the proposed scheme to enhance the transient performance of the salient PMSM drive. Finally, the proposed speed control strategy reveals a fast-transient speed response when compared to the conventional dual current loop PI-based speed controller over extended speed range and load torque variations. The computer simulation conducted using MATLAB/Simulink and experimental results obtained using PMSM laboratory prototype are presented considering constant torque and constant power regions to confirm the efficacy of the proposed speed control strategy.
\end{abstract}

Keywords: Augmented state Kalman filter (ASKF); electric vehicles (EVs); Constant power regime; permanent magnet synchronous motor (PMSM); predictive speed control.

\section{INTRODUCTION}

With great engulfed efforts on flattening global climate change effects, electrification of transport sector has been one of the focal solutions. In this case, electric vehicles (EVs) in the form of hybrid EV, all electric EV and fuel-cell EV are becoming attractive alternatives for road transportation (Chan, 2007; Du et al., 2019; Ehsani et al., 1997). Renowned automobile manufacturers like Toyota, Nissan and General Motor have entered the EV market (Santiago,. 2012). Technically, the EV drives have speed and torque requirements to mimic internal combustion engine vehicle (ICEV) such as high torque to size ratio, high power to size ratio, extended angular speed range that is mutually circumscribing low speed and high-speed cruising mode, large constant power operating capability (even deep flux weakening region), high recurrent overload ability to overtake and sufficiently manage hill climbing (Chan et al., 1996; Huynh and Hsieh, 2018; Chau, 
2017).

To this end, most modern EV drive applications require high performance control that guarantees a wide speed range operation with fast transient speed and torque responses while demonstrating quick recovery from any disturbance (Wei et al., 2020). Most of EV tractions require fast speed and torque responses to achieve desired high speed in very short time. For the case of 2020 Tesla Model X electric vehicle, performance model can accelerate zero to $60 \mathrm{mph}$ in 2.7 seconds (EV Specification, 2020). This kind of EV performances not only display fast speed response, but also necessitate highperformance speed and current control schemes with effective tracking features even beyond rated speed to meet cruising or very high speed.

Electric vehicle brands such as Toyota Prius and Ford Escape incorporate salient permanent magnet synchronous motors in their traction system (Rajashekara, 2013). PMSM has attracted electric vehicle traction application as it embraces most of the above EVs performance requirements. Particularly, IPMSM encirclements high efficiency and torque capability at low speed below base (constant torque region) and high extended speed operating range covering constant power region (Justo and Mwasilu, 2019; Kim, 2012; Zhang et al., 2016).

Conventionally, to accomplish both speed and current control of the AC drives, the dual proportional-integral vector control has been extensively employed (Sul, 2011; Wang et al., 2015). The conventional dual PI controller is devised to operate within the linear region of the closed-loop system and hence performance highly deteriorates with nonlinear machine dynamics like saturation nonlinearities. This may result in large overshoot, slow settling time, and at some point, may escalate system instability during transients (Vukosavić, 2007). Nevertheless, the nonlinear characteristic of the salient PM synchronous motor and inadequate bandwidths of the dual current loop PI control scheme prominently deprive the excellent transient performance of the motor drive. To compromise for the nonlinear characteristics of the PMSM, dual PI-based speed controllers are universally substituted with the nonlinear control schemes to acquire highperformance speed and torque dynamics (Choi and Jung, 2012; Kim and Youn, 2002). Plentiful nonlinear control techniques have been investigated to tackle the speed and torque control task of the IPMSM drive for EV applications such as fuzzy logic control (Justo et al., 2017) artificial neural network (ANN) control (Leu et al., 2014) and sliding mode control (Liu et al., 2018).

Lately, advances in digital control computation technology have escalated the feasibility of model predictive control schemes in electric machine drive applications (Rodriguez and Cortes, 2012; Geyer, 2017). In particular, the model predictive control (MPC) emerges as an optimal-based control scheme that minimizes the error between predicted parameters and desired signals. Nonlinear constraints can be easily included in one particular control law to accommodate various machine operational requirements (Wang, 2009). In model predictive control design and employment, the system mathematical model is employed to forecast the forthcoming characteristics of multi-variable states and the objective cost function is recalled to compute the optimum switching actions of the salient PMSM drive (Fuentes et al., 2012; Mynar et al., 2016). The MPC control design is flexible and has a simple structure with powerful control performances compared 
to the above-mentioned nonlinear control schemes (Kang et al., 2020; Liu et al., 2018). Particularly, the proposed MPCbased scheme has advantages such as fast transient response and more compact formulation for speed control of the IPMSM in wide speed range.

In this paper direct peed control technique based on MPC approach is proposed. The proposed direct speed MPC scheme lumps both rotor speed and stator current in one cost function. The proposed scheme demonstrates high control performance features such as rapid dynamic speed characteristics and excellent tracking capabilities over a wide speed range when compared to the conventional cascade PI speed controller. Similarly, the proposed model predictive speed demonstrates high robust features under sudden external disturbance and model parameter variations. The efficacy of the proposed model predictive speed control are validated through the comparative computer simulation and experimental results under load torque variations, constant torque and constant power/flux weakening regions.

\section{IPMSM MODELLING WITH CONSTANT TORQUE AND CONSTANT POWER REGIONS}

\section{IPMSM Predictive Model}

The dynamic mathematical model of the salient PMSM is derived in synchronous rotating direct and quadrature axis as described in Sul (2011) and Wang et al. (2015). Since the discrete-time model is essential for predictive speed control design, then, the Forward Euler discretization method is employed to obtain equations (1) and (2) (Rodriguez and Cortes, 2012).

$$
\begin{aligned}
& \left\{\begin{array}{l}
i_{d s}(k+1)=\left(\left(\left(L_{d}\right)^{-1} i_{d s}(k)-i_{d s}(k) T_{s} R_{s}\left(L_{d}\right)^{-1}\right)+T_{s} \omega_{r}(k) i_{q s}(k)+T_{s} V_{d s}(k)\left(L_{d}\right)^{-1}\right) \\
i_{q s}(k+1)=\left(\left(\left(L_{q}\right)^{-1} i_{q s}(k)-i_{q s}(k) T_{s} R_{s}\left(L_{q}\right)^{-1}\right)-T_{s} \omega_{r}(k) i_{d s}(k)-T_{s} \omega_{r}(k) \Psi_{m}+T_{s} V_{q s}(k)\left(L_{q}\right)^{-1}\right)
\end{array}\right. \\
& \left\{\begin{array}{l}
\omega_{r}(k+1)=\left(\omega_{r}(k)-\left(J_{m}\right)^{-1}\left(\omega_{r}(k) T_{s} B_{m}\right)\right)+0.5 T_{s} p\left(J_{m}\right)^{-1}\left(T_{e}(k)-T_{L}(k)\right) \\
T_{e}(k+1)=0.75 p\left(\Psi_{m} i_{q s}(k+1)+i_{d s}(k+1) L_{d q} i_{q s}(k+1)\right)
\end{array}\right.
\end{aligned}
$$

Where $L_{d q}$ implies stator inductance saliency of the PM machines, $V_{d s}$ and $V_{q s}$, are the stator voltages while $L_{d}$ and $L_{q}$ are the direct- and quadrature-axis stator inductances, $\omega_{r}$ is an electrical rotor angular speed, $T_{s}$ represents sampling rate that implies control refreshing rate. $J_{m}$ symbolizes the total moment of inertia of the electric PM machine. $i_{d s}$, and $i_{q s}$ are direct- and quadrature-axis stator winding currents, respectively, and $p$ represents number of poles of the laboratory prototype PM machine. $R_{S}$ is a stator winding resistance whereas $T_{L}$ is the load torque, which is normally an uncertain disturbance to be suppressed and $T_{e}$ is the electric torque. $\Psi_{m}$ is the flux linkage of the PM machine.

Note that $V_{d s}$ and $V_{q s}$ signifies $d q$-axis control input voltages obtained as a function of the two-level inverter switching states $\left(S_{j}\right)$, which are defined in equation (3) (Wang et al., 2015).

$$
\left\{\begin{array}{l}
V_{d q s}^{j}(k)=\left[V_{d s}(k) V_{q s}(k)\right]^{T}=f\left(S_{j}\right) \\
j=\in\{1,2 \ldots 7\} \\
S \in\left\{S_{a}(k), S_{b}(k), S_{c}(k)\right\} \\
S_{a} \in\{0,1\}, S_{b} \in\{0,1\}, S_{c} \in\{0,1\} \\
S_{j} \in\{000 ; 100 ; \ldots 101 ; 111\}
\end{array}\right.
$$


IPMSM Drive Descriptive

Characteristic Features in Constant Torque and Constant Power Regimes

Underneath the base speed, the salient PMSM drive is controlled to optimize the electric torque generation while simultaneously curtailing copper losses at constant torque operating regime. Similarly, the control regime is confined within a stator current locus following the line $O G$ as portrayed in Figure 1. In maximum torque control mode, the directaxis stator current is calculated as in equation (4) until the base speed is attained. This locus is normally known as maximum torque per ampere (MTPA). Correspondingly, the operation of the salient PMSM drive above base speed is achieved by imposing the direct-axis stator current to diminish the excessive magnetic flux linkage. In this case, the speed limit of the IPMSM drive can be highly extended (Sul, 2011; Liu et al., 2018). Figure 1 shows the operating regions of salient PMSM drive under wide speed range confined in stator voltage and current loci. As shown in Fig. 1, the intersecting point between the maximum stator voltage locus $\left(\omega_{1}\right)$ and maximum stator current locus gives the base operating point of the IPMSM (i.e., at point $G$ ).

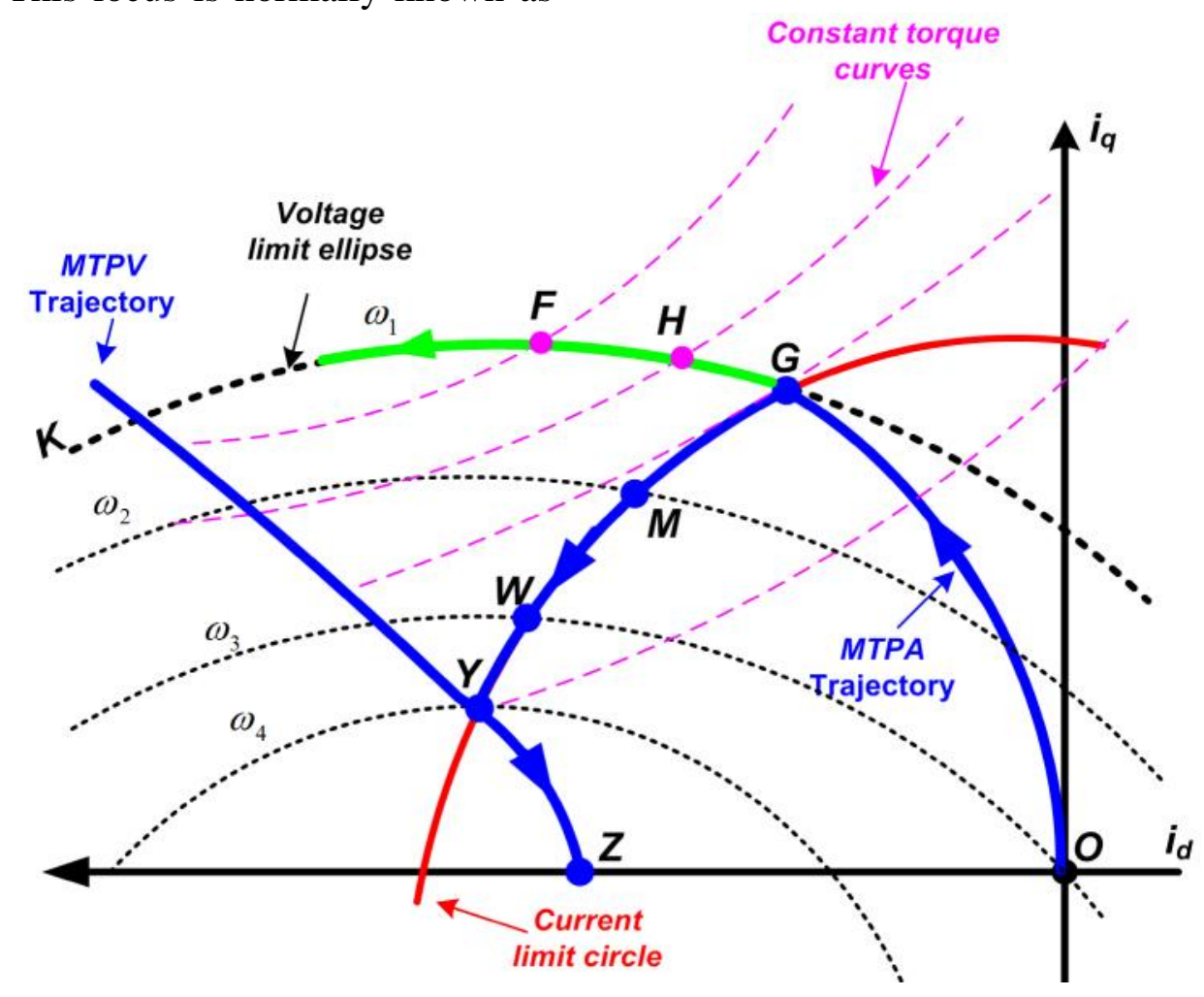

Figure 1: Operating regions of an IPMSM drive under wide rotor speed range with voltage and current limits loci

However, above rated speed (beyond $G$ ) the operating point will be off-MTPA trajectory control and it will therefore trace a path along maximum current limit ellipse (i.e., along $G M W Y$ ) while enforced to satisfy the maximum voltage limit of the drive. This occurs as the drive speed keeps on increasing beyond rated speed. On the other hand, considering fixed rated rotor speed beyond $G$ and with increase in torque demand (i.e., along $G H F$ ) the current vector violates the maximum current limit, which may result in current control saturation (ultimately less torque production) (Kim, 2012; Sul, 2011). The point of intersection between the 
respective voltage limit ellipses and the constant torque curves (i.e., illustrated by points $G, H$, and $F$ ) becomes the optimum point in order to attain minimum copper loss.

$$
i_{d s}(k)=0.25 \Psi_{m}\left(L_{d q}\right)^{-1}-\sqrt{\frac{\Psi_{m}^{2}}{16\left(L_{d q}\right)^{2}}+} \frac{I_{a}^{2}}{2}
$$

Furthermore, as the rotor speed increases along trajectory $M W Y$ the maximum torque should be reduced to maintain voltage limit. Note that the IPMSM drive is controlled in this mode by invoking $d$ axis stator current to weaken flux linkage in the stator as depicted in equation (5). It will reach a speed operating point where further increase will not satisfy the maximum voltage limit criteria of the IPMSM drive. In this context, at point $Y$ with rotor speed $\left(\omega_{4}\right)$ is the minimum

$$
i_{d s}(k)=\frac{L_{d} \Psi_{m}-\sqrt{\left(L_{d} \Psi_{m}\right)^{2}+\left(L_{q}^{2}-L_{d}^{2}\right)\left[\Psi_{m}^{2}+\left(L_{d} I_{a m}\right)^{2}-\frac{V_{a m}}{\omega_{r}}\right]}}{L_{q}^{2}-L_{d}^{2}}
$$

speed for the operating point to stay within voltage limit. The control trajectory at this point is known as maximum torque per voltage (MTPV) with the stator current vector at $Z$. To this end, the direct speed control of the salient PMSM drive is achieved from low speed below base $\left(\omega_{1}\right)$ passing through base speed to very high speed beyond base at $\omega_{4}$ where a deep flux-weakening control region is realized along the MTPV trajectory.
It is important to note that the stator current limit $\left(I_{a m}\right)$ is evaluated by considering heating and current carrying capacity of the electric machine drive system while the stator voltage limit $\left(V_{a m}\right)$ is bounded by the dc-voltage range $\left(V_{D C}\right)$ of the power inverter.

$$
\begin{aligned}
& \left\{\begin{array}{l}
\sqrt{i_{d s}^{2}+i_{q s}^{2}} \leq I_{a m} \\
\sqrt{V_{d s}^{2}+V_{q s}^{2}} \leq V_{a m}
\end{array}\right. \\
& V_{a m}=\frac{V_{D C}}{\sqrt{3}}
\end{aligned}
$$

\section{Direct Predictive Speed Control Design}

The proposed direct predictive speed control scheme is designed to include the angular speed and stator current state variables in a single objective cost function inspired by MPC design. For prediction of salient PMSM system at every switching interval, the forward Euler discretization technique with sampling interval $T_{S}$ is adopted to emulate the machine model as depicted in equations (1) and (2).

\section{Direct Predictive Speed Control Design and Formulation}

The predictive speed control design permits various parameters to be encapsulated in single cost function. The state control variables such as rotor speed and $d q$-stator currents should sum up to minimize their state errors, which signify minimum steady state errors. This flexibility allows different parametric state control variables to be cast in a single predictive objective function considering various control targets. Then, the cost function is confined to diminish the overall state errors. Contextually, the proposed predictive speed control is based on the cost function represented by equation (8) that includes angular speed and stator current predictions with machine operating constraints. All these parameters are evaluated at once in every sampling interval. 


$$
\begin{aligned}
& \Xi_{\mathrm{cf}}(.)=\left[\left(\Delta \omega_{r}(k+2)\right)^{2}+\Lambda_{i d s}\left(\Delta i_{d s}(k+2)\right)^{2}+\Pi_{v a-L i m}+\Theta_{i a-L i m}\right] \\
& \Delta \omega_{r}(.)\left|\omega_{r}^{r e f}(.)-\omega_{r}(.)\right| \text { and } \Delta i_{d s}(k+2)=\left|i_{d s}^{r e f}(.)-i_{d s}^{r e f}(.)\right|
\end{aligned}
$$

Where $\omega_{r}^{r e f}$ is a desired or reference rotor speed, $\Delta_{i d s}$, is a positive constant weighting factor while $\Pi_{v a-L i m}$, and $\Theta_{i a-L i m}$ are nonlinear stator voltage and current parametric constraint functions to enforce the salient PMS motor drive operation regime circumscribed in their constraint permissible limits.

The positive weight is designed to influence the cost function evaluation so that it weighs more the errors. Subsequently, the voltage vector(s) that lead to higher errors have lower priority in optimal voltage vector selection criterion. In fact, the optimal voltage vector is qualified accepted if it results in overall minimum error. For example, the positive weight $\Delta_{i d s}$ is intended to penalize the $d$ axis stator current errors so that the voltage vector which results into large current errors has no chance to be selected. This is accomplished while taking into account that the IPMSM drive is confined within the constant torque region with MTPA trajectory (i.e., below base rotor speed) and flux weakening control (i.e., beyond base speed). It can be observed from equation (8) that in most of the speed transient regions the speed errors will highly influence the overall state errors and hence, the main objective will rely on minimizing of the speed errors whereas in steady-state the MTPA or flux weakening regions will be of much interest (i.e., the $d$ axis current errors will influence more state errors) as the speed errors are expected to be minimal (i.e., high speed tracking ability).

\section{Observer-Based Direct Speed Predictive Control Design}

The main task of a speed controller for IPMSM drive is to indirectly generate the driving torque that keeps the actual speed tracks its set point as a result the speed error reduces to zero. This speed error is influenced by the input disturbance (i.e., speed reference) or external disturbance (i.e., load torque variations). Based on this observation, it is important to suppress any external disturbances for the effective IPMSM drive operation especially with EVs applications in mind. If this unknown disturbance is sufficiently suppressed, it significantly escalates speed tracking errors and overshoots when the PMSM drive is subjected to step response modes. This scenario may happen when the EV subjected to sudden overtaking while cruising. Consequently, it affects the overall system dynamics of the EV drive operation.

It has been noted that the unknown disturbance $T_{L}$ has direct impact on the system state. Definitely, estimating $T_{L}$ in the presence of the system states is the promising solution. This can be simply accomplished by treating the unknown disturbance $T_{L}$ as part of the system states, this estimation problem is generally formulated as an augmented state Kalman filter (ASKF) with two decoupled parallel Kalman filters referred to here as extended modified ASKF (Haessig and Friedland, 1998).

The nonlinear-stochastic discrete-time state model is depicted in equation (9) based on the dynamic salient PMSM mathematical model. In this formulation, the unknown load torque disturbance is treated as an augmented state $\tilde{\eta}(k)=T_{L}(k)$ and remains constant within sampling interval period. 


$$
\left\{\begin{array}{l}
{\left[i_{d s}(k+1) i_{q s}(k+1) \omega_{r}(k+1) \theta_{r}(k+1)\right]^{T}} \\
=\Gamma(k)\left[i_{d s}(k) i_{q s}(k) \omega_{r}(k) \theta_{r}(k)\right]^{T}+\tilde{\mathrm{H}} T_{L}(k)+B(k)\left[V_{\alpha}(k) V_{\beta}(k)\right]^{T}+\xi(k) \\
T_{L}(k+1)=T_{L}(k)+\tilde{\xi}(k) \\
{\left[i_{\alpha}(k+1) i_{\beta}(k+1)\right]^{T}=C(k)\left[i_{\alpha}(k) i_{\beta}(k)\right]^{T}+\varsigma(k)}
\end{array}\right.
$$

while $V(k)$ is an input voltage vector with $V_{\alpha}(k)$ and $V_{\beta}(k)$ being in $\alpha \beta$-axis reference frame concomitant with $d q$-axis voltage vectors $V_{d s}(k)$ and $V_{q s}(k)$. Similarly, the stator winding currents $i_{\alpha}(k)$ and $i_{\beta}(k)$ are in $\alpha \beta$-axis reference frame. $\xi(k)$ exemplifies the nonlinear parametric vector that accounts for uncertain system dynamics whereas $\zeta(k)$ depicts the measurement noise vector. Both $\xi(k), \tilde{\xi}(k)$, and $\zeta(k)$ are assumed to be uncorrelated white Gaussian sequences with zero mean. This forms the noise covariance matrices defined as $Q(k)$ and $R(k)$, respectively. The system and unknown disturbance states can be projected repeatedly in two-step cascaded filter process: state variables' forecast and state variable forecastcorrection (Haessig and Friedland, 1998).

Therefore, the estimated state vector $\hat{X}()=.\left[i_{d o}(.), i_{q o}(.), \omega_{r o}(.), \theta_{r o}(.), T_{L o}(.)\right]^{T}$ co nsidering together the modified system state and augmented state $\tilde{\eta}(k)$ (Haessig and Friedland, 1998).Based on the estimated states the IPMSM prediction model in equations (1) and (2) can be reformulated to obtain the complete observer-based prediction algorithm as follows:

$$
\begin{aligned}
\begin{aligned}
\hat{i}_{q s}(k+2)= & -\omega_{r o}(k+1) i_{d o}(k+1) T_{s} L_{d}\left(L_{q}\right)^{-1}-i_{q o}(k+1) T_{s}\left(L_{q}\right)^{-1} R_{s}+V_{q s}(k+1) T_{s}\left(L_{q}\right)^{-1} \ldots \\
& -T_{s} \Psi_{m}\left(L_{q}\right)^{-1} \omega_{r o}(k+1)+i_{q o}(k+1)
\end{aligned} \\
\begin{aligned}
& \hat{i}_{d s}(k+2)=\omega_{r o}(k+1) T_{s} L_{q} i_{q o}(k+1)\left(L_{d}\right)^{-1}-i_{d o}(k+1) T_{s}\left(L_{d}\right)^{-1} R_{s}+V_{d s}(k+1) T_{s}\left(L_{d}\right)^{-1}+i_{d o}(k+1) \\
& \widehat{\omega}_{r}(k+2)=-\omega_{r}(k+1) T_{s} B_{m}\left(J_{m}\right)^{-1}+0.75 p^{2} \hat{i}_{q s}(k+2)\left(J_{m}\right)^{-1} T_{s} \Psi_{m}-0.5 p T_{L o}(k+1) T_{s}\left(J_{m}\right)^{-1} \ldots \\
&+0.75 p^{2}\left(J_{m}\right)^{-1} \hat{i}_{d s}(k+2) T_{s} L_{d q} \breve{i}_{q s}(k+2)+\omega_{r}(k+1)
\end{aligned}
\end{aligned}
$$

The predicted states are applied to the proposed direct predictive speed control

\section{DSPC Scheme Performance Evaluation}

The proposed direct predictive speed control (DSPC) scheme has been confirmed through MATLAB/Simulink simulation results and experiment on a DSP-based laboratory prototype. Table I presents all the parameters of the prototype employed in this paper. The control comparative performance is made with the conventional dual loop PI speed control scheme in constant torque and constant law in equation (8).

power regimes. The parameters of the considered dual PI scheme are designed using design philosophy described in (Sul, 2011; Wanget al., 2015; Vukosavić, 2007). The performance criteria that have been chosen to comparatively assess the dual loop PI-based controllers and the proposed direct speed predictive control are fast-transient responses of the two controllers. For fair comparison, the damping ratio is set to a 0.71 to guarantee complex conjugate poles for fast 
responses. For the same reasons, bandwidth of the current control loop is designed to be twenty times that of the speed loop (Wang et al., 2015; Vukosavić, 2007). In this paper, a pre-filter is employed to compensate for the overshoots imposed by the closed-loop zeros contributed by the PI transfer function. Nevertheless, the parameters of the predictive speed control in equation (8) are designed to heavily penalize the speed errors to consequently enhance the angular speed tracking performance with current and voltage limit constraints enforced.

\section{Performance Evaluations with Simulation Results}

Simulation results for the controllers' performance are first evaluated under various rotor speed and load torque dynamics. Since the IPMSM drive is evaluated under two different speed dynamics in Scenario I, the speed step change is first considered. Note that the desired or reference rotor speed symbol $\omega_{r}^{r e f}$ defined earlier in equation (8) is replaced by $\omega_{d}$ throughout result discussion.

Figure 2 presents the computer simulation results of the dual loop PI controller and direct predictive speed control (DSPC) scheme tested under angular speed step change command. In this case, the rotor speed is step changed from 800 to 1200 $\mathrm{r} / \mathrm{min}$ and the load torque is set constant to $1 \mathrm{Nm}$.

It was observed that the proposed DSPC strategy exhibited quicker speed response when compared to the conventional dual current loop PI-based control method as a result of direct application of the optimum converter switching actions and the lumped feature of the DSPC approach. It is confirmed by a small rise time $(5.3 \mathrm{~ms})$ and a short settling time $(7.6 \mathrm{~ms})$ of the proposed DSPC scheme in comparison with $40.5 \mathrm{~ms}$ and $120.6 \mathrm{~ms}$ of the revealed in Figures 2(a) and 2(b), respectively. It is evident that the precise speed control is achieved by the proposed DSPC scheme with quicker dynamic response than the PI controller.

Table 1: Parameters of an Experimental IPMSM Drive Prototype

\begin{tabular}{|c|c|c|c|}
\hline Symbol & Parameter & Value & Unit \\
\hline$T_{\text {rated }}$ & Rated torque & 1.5 & $\mathrm{~N} \cdot \mathrm{m}$ \\
\hline$\omega_{\text {rated }}$ & Rated speed & 2500 & $\mathrm{r} / \mathrm{min}$ \\
\hline$R_{s}$ & $\begin{array}{c}\text { Stator } \\
\text { resistance }\end{array}$ & 2.48 & $\mathrm{mH}$ \\
\hline$L_{q}$ & $\begin{array}{c}q \text {-axis } \\
\text { inductance }\end{array}$ & 113.91 & $\mathrm{mH}$ \\
\hline$L_{d}$ & $\begin{array}{c}d \text {-axis } \\
\text { inductance }\end{array}$ & 74.98 & $\mathrm{~Wb}$ \\
\hline$\lambda_{m}$ & $\begin{array}{c}\text { Magnet flux } \\
\text { linkage }\end{array}$ & 0.193 & $\mathrm{~kg} \cdot \mathrm{m}^{2}$ \\
\hline$J$ & $\begin{array}{c}\text { Equivalent rotor } \\
\text { inertia }\end{array}$ & 0.00042 & $\begin{array}{c}\mathrm{N} \cdot \\
\mathrm{m} \cdot \mathrm{s} / \mathrm{rad}\end{array}$ \\
\hline$B$ & $\begin{array}{c}\text { Viscous friction } \\
\text { coefficient }\end{array}$ & 0.0001 & $\mathrm{~V}$ \\
\hline$V_{D C}$ & DC-link voltage & 295 & $\mathrm{~s}$ \\
\hline$T_{s}$ & Sampling time & 100 & \multicolumn{2}{|c}{} \\
\hline
\end{tabular}

On the other hand, Figure 3 presents the simulation results of the conventional dual current loop PI-based control method and the DSPC method obtained during sudden external load torque variations, respectively. The sudden load torque step change is applied from 0.6 to $1.5 \mathrm{Nm}$ at steady angular speed of $1000 \mathrm{r} / \mathrm{min}$. In Figure 3, high overshoots $(33.2 \%)$ are revealed on the angular speed response of the conventional control scheme. These results are influenced by the poor disturbance rejection of the conventional dual current loop PI-based speed controller when subjected to the sudden external disturbances. It is very clear that the electric torque and angular speed results for the conventional cascaded PI scheme are not rapidly returned to their normal operating conditions. Therefore, resulted in longer settling periods $116.9 \mathrm{~ms}$ and 45.7 $\mathrm{ms}$, respectively as shown in Figure 3(a) whereas, the proposed DSPC scheme in Figure 3(b) demonstrates an excellent 
Direct Predictive Speed Control of Salient PMSM Drives in Constant Torque and Constant Power Regimes for Electric Vehicles Applications

performance with the fastest transient responses (less than $10 \mathrm{~ms}$ ) and almost no significant overshoot $(0.1 \%)$ because of the disturbance rejection technique by the proposed ASKF observer. The excellent disturbance rejection response of the proposed direct PSC scheme is also revealed with the coordination of the proposed ASKF by providing a precise estimated external load torque, $T_{L o}$. All these performances are confirmed by the system responses shown in Figure 3(b).

Furthermore, the performance characteristics of the proposed DSPC were evaluated under extended angular speed range, below and above rated speed. The operational features of the salient PMSM drive in constant power regime (i.e., flux weakening region) are assessed under the proposed model DSPC scheme. Figure 4 exemplifies the computer simulation results of the direct PSC technique in the extended angular speed range beyond the base speed (i.e., the desired rotor angular speed $\left(\omega_{d}\right)$ beyond $2500 \mathrm{r} / \mathrm{min}$. Precisely, first the motor is subjected to a step command signal1300 to $2450 \mathrm{r} / \mathrm{min}$ as revealed in Figure 4(a). In this case, the maximum torque is attained and the motor is controlled to follow the MTPA trajectory. Excellent tracking ability is revealed and the stator currents stay within their operating limits.
Furthermore, the motor drive angular speed is given a fresh step command 1300 to $3000 \mathrm{r} / \mathrm{min}$ as exemplified in Figure 4(b) to operate above base speed. The voltage limit is violated when the salient PMSM drive is operated beyond the base value of the rotor angular speed unless special measures such as air gap flux regulation have been taken to counteract that adverse condition. Thus, the motor will attain this constant power regime by recalling flux weakening control where the $d$-axis current regaining more in negative region so as to weaken the air-gap flux. As a result, the maximum torque response cannot be achieved anymore in this constant power region. Hence, a reduced torque is revealed in Figure 4(b) before the PMSM drive regaining its steady-state conditions, which is contrary to the operation below base speed as demonstrated in Figure 4(a). This is due to the fact that the system states should act to satisfy the voltage limit constraints. The simulation results shown in Figure 5 confirm that the salient PMSM drive is entirely regulated by employing the proposed direct speed predictive control in a constant torque regime through the precise tracking of the MTPA vector locus and constant power region (i.e., revoking magnetic flux linkages) as elaborated in Section IIB and further illustrated by Figure 1. 

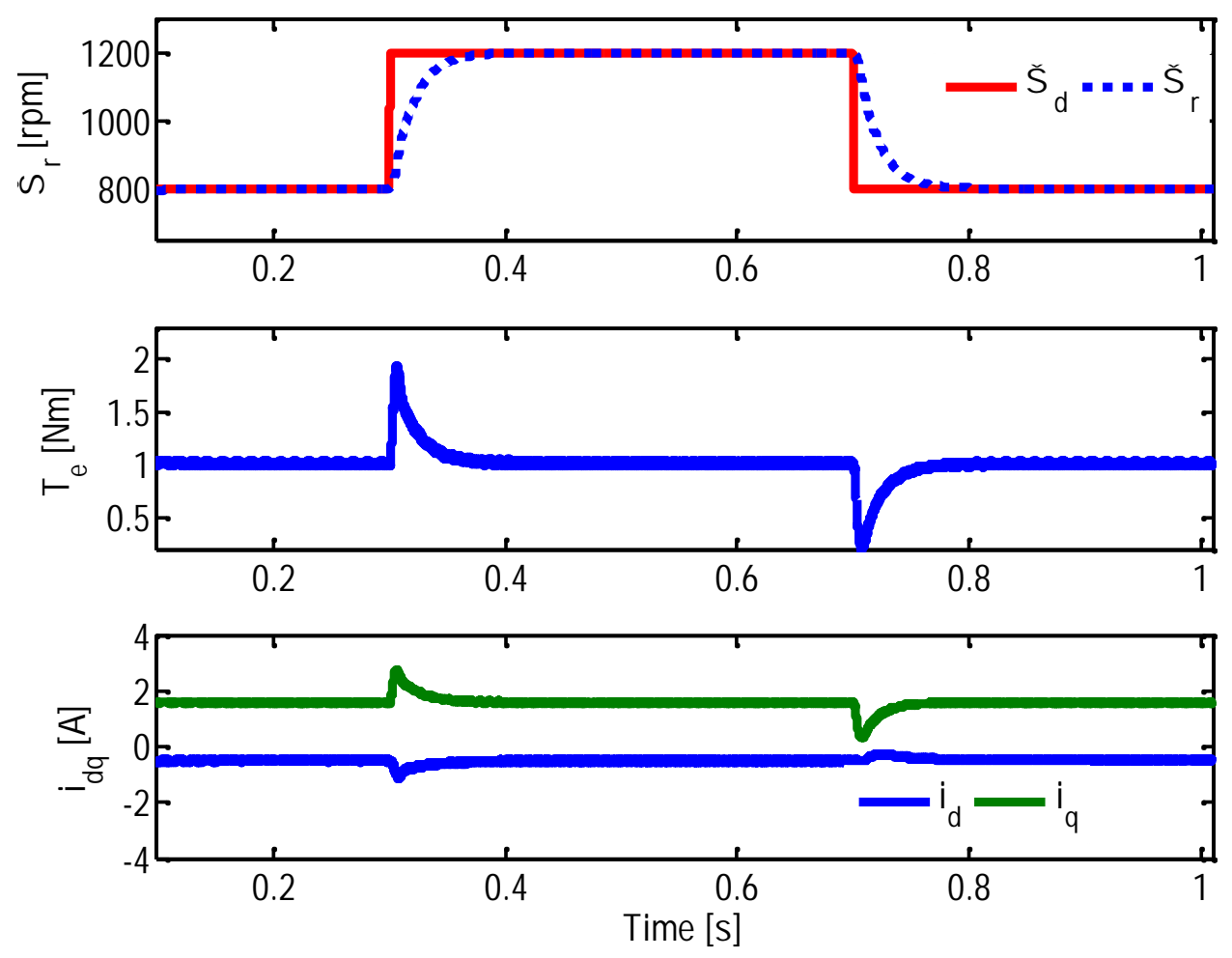

(a)
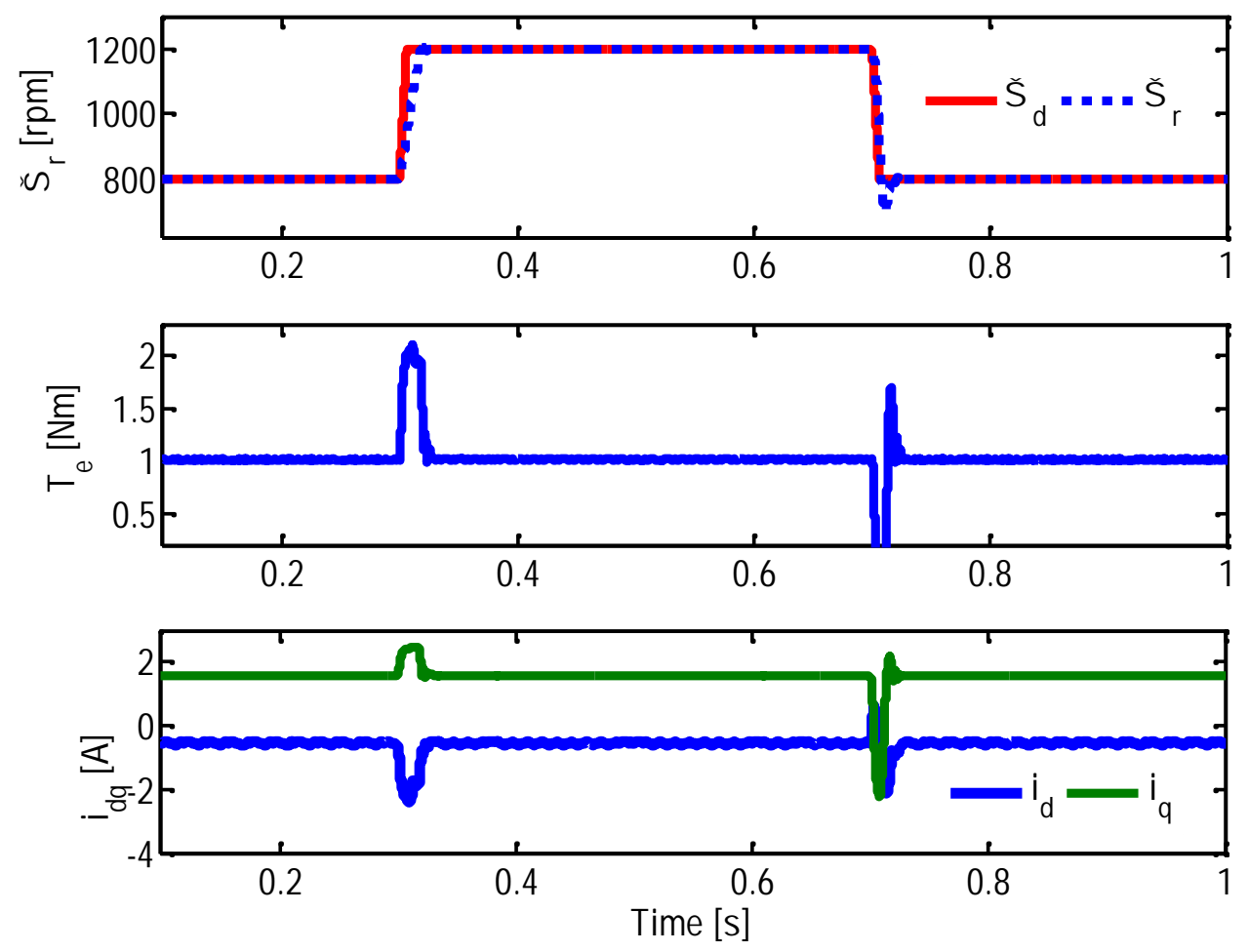

(b)

Figure 2: Simulation results with rotor angular speed step command. (a) Dual current loop PI control strategy. (b) DSPC control strategy 
Direct Predictive Speed Control of Salient PMSM Drives in Constant Torque and Constant Power Regimes for Electric Vehicles Applications
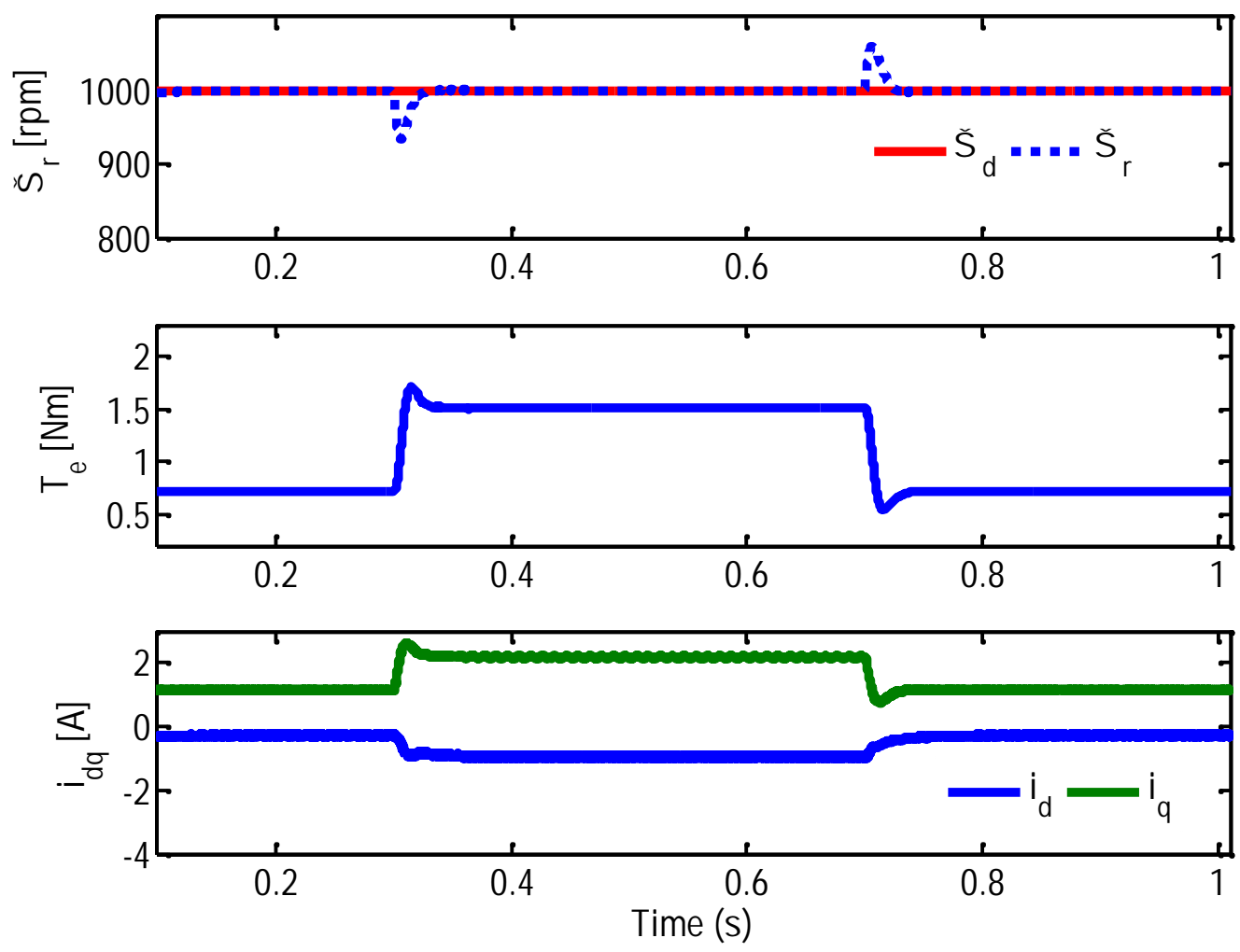

(a)
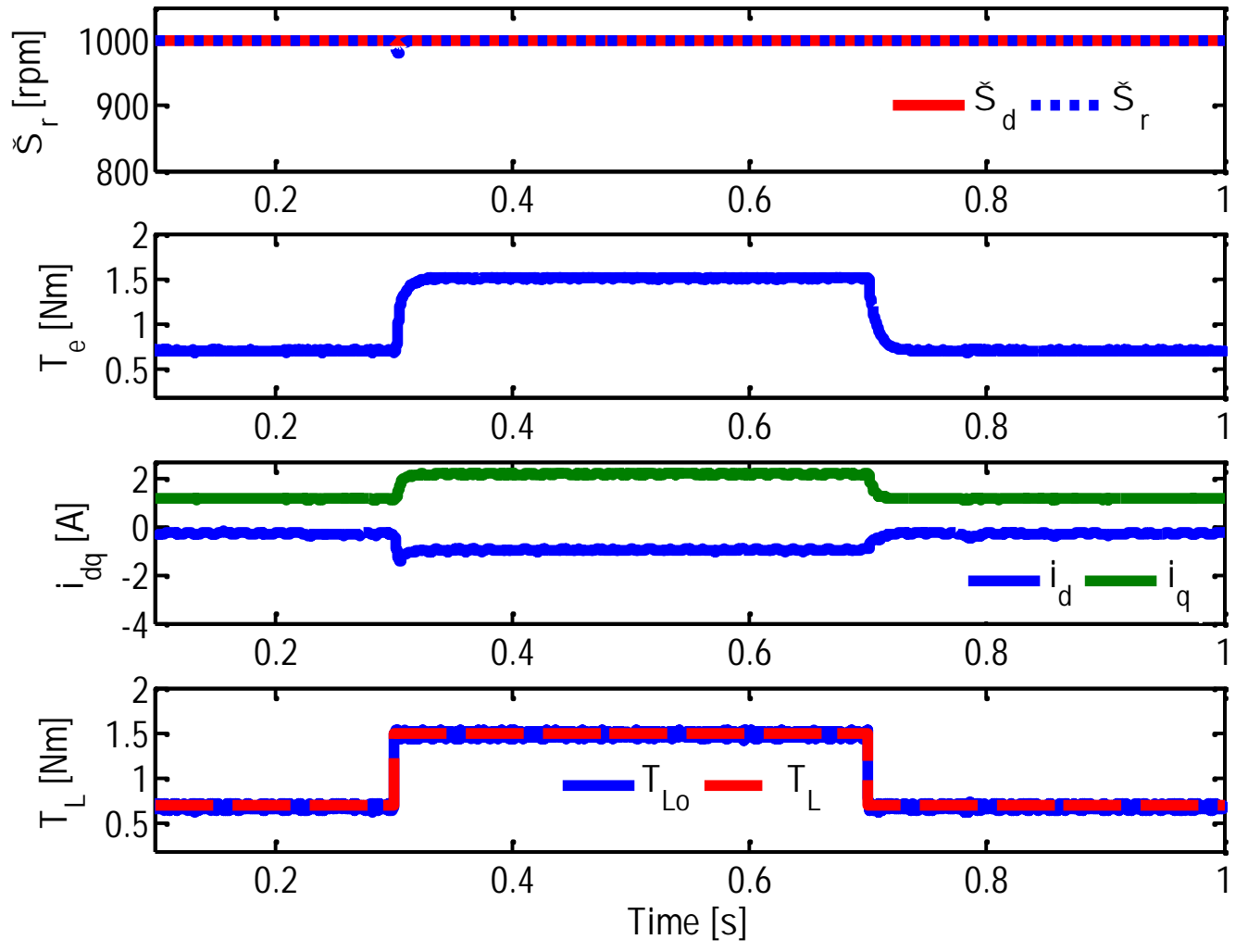

(b)

Figure 3: Simulation results with load torque step command. (a) Dual current loop PI control strategy. (b) DSPC control strategy 

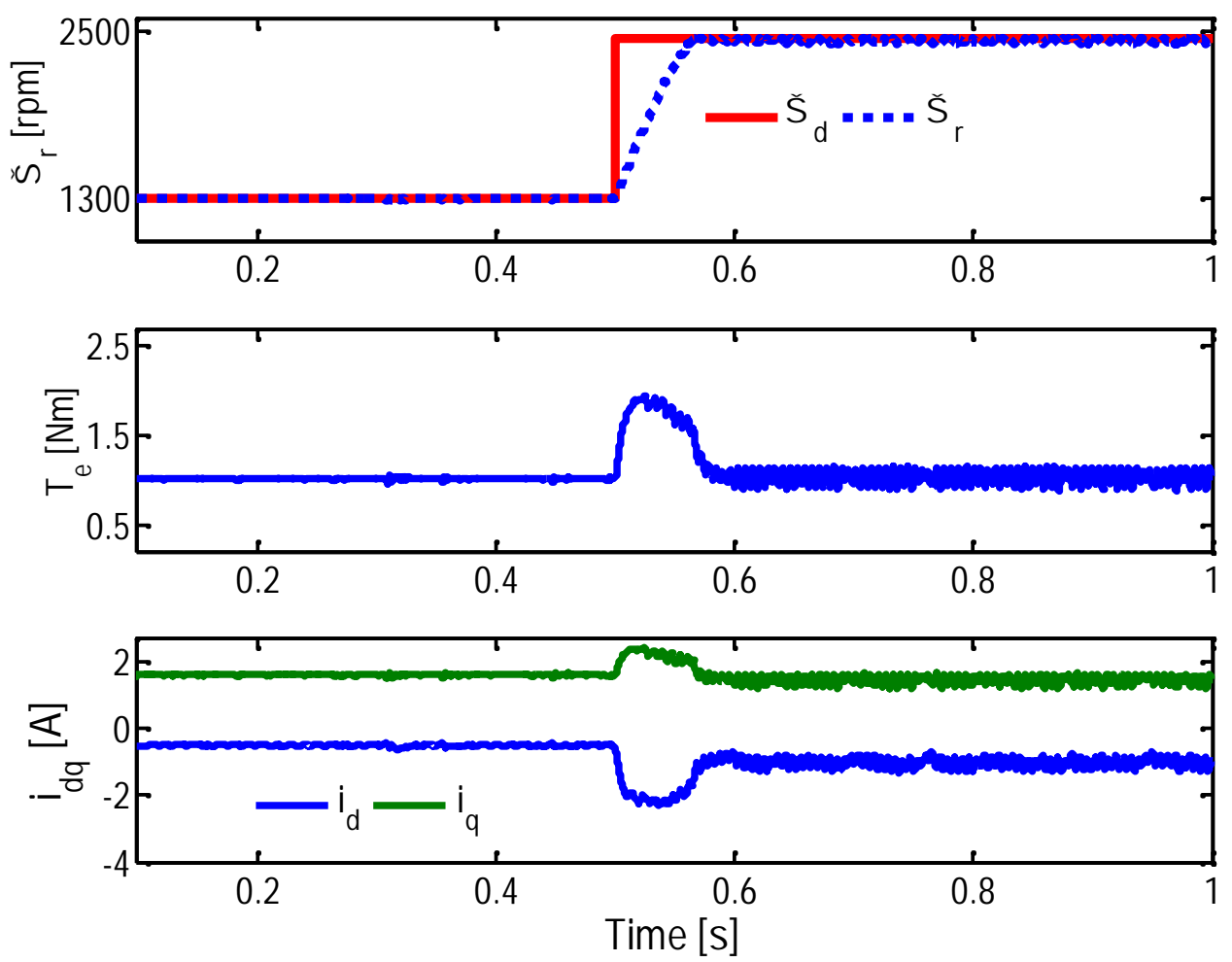

(a)
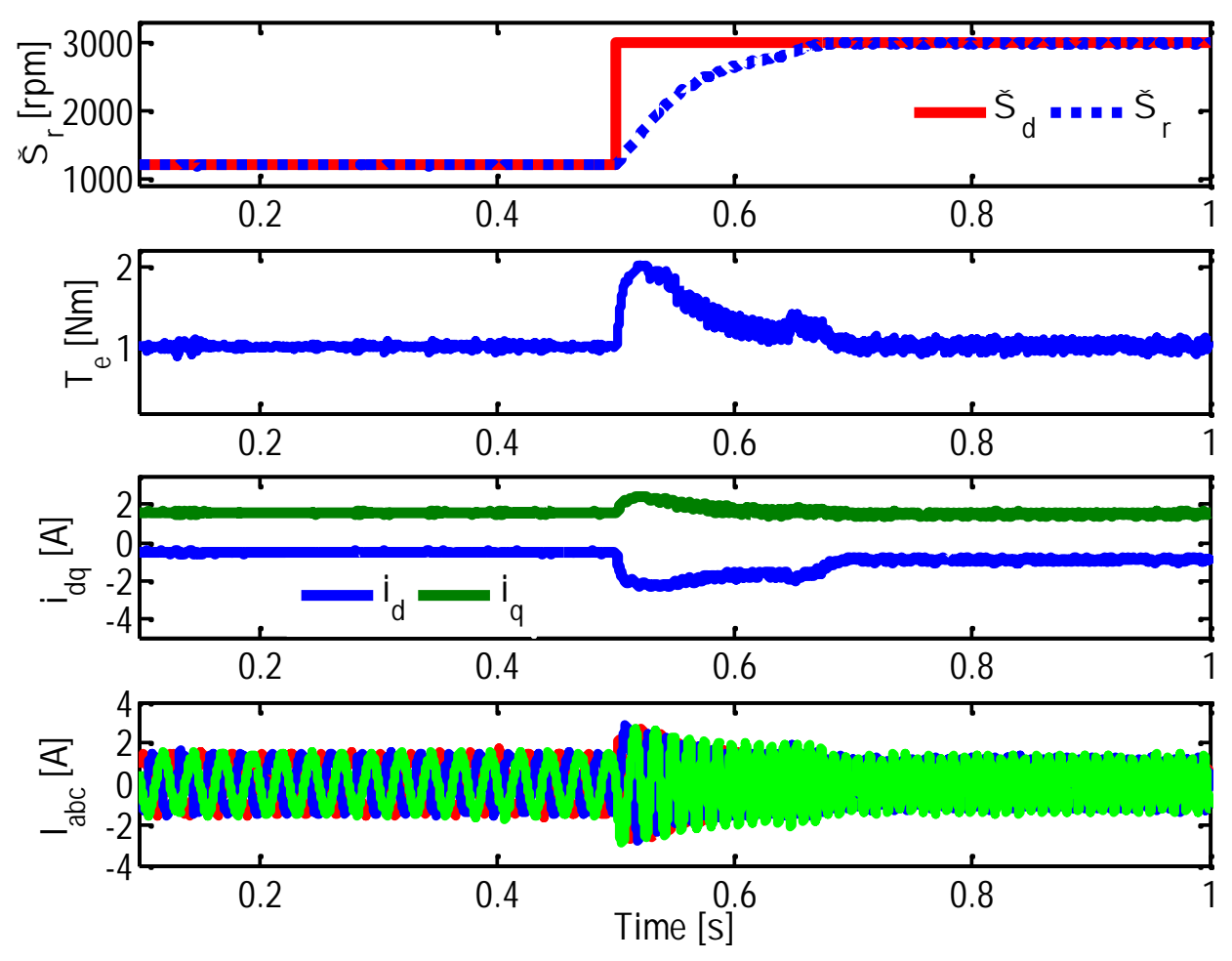

(b)

Figure 4: Simulation results of the DSPC strategy in extended rotor angular speed (a) Constant torque region (b) Flux weakening region 


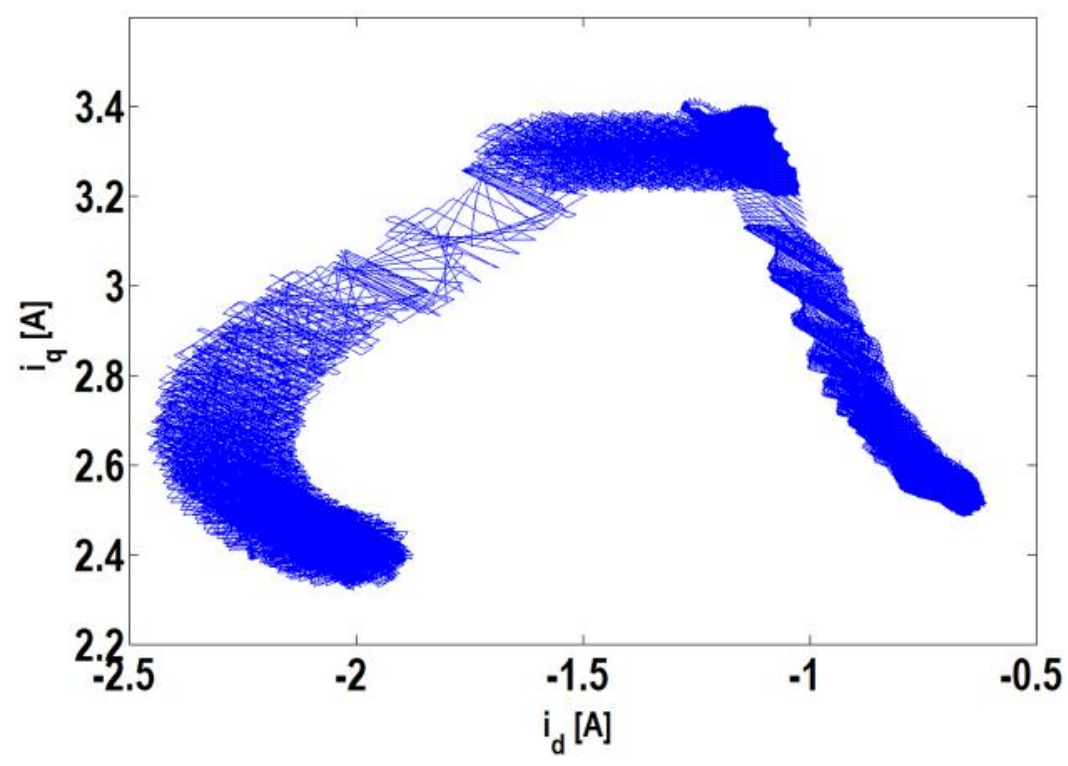

Figure 5: Simulation results of the direct- and quadrature- axis stator current locus obtained by employing DSPC control strategy in a constant torque and constant power regimes under light load condition

\section{PERFORMANCE EVALUATIONS WITH EXPERIMENTAL RESULTS}

The laboratory IPMSM drive prototype was set and configured as shown in Figure 6 with electric brake used as load of the IPMSM under test, $\omega_{r}^{*}(k)$ and $i_{d}^{*}(k)$ denotes the desired or reference rotor angular speed and $d$-axis stator current at periodical instant $k$, respectively. Other symbols in Figure 6 retain their usual definition described earlier. On the other hand, the proposed DSPC and conventional dual current control loop PIbased scheme were programmed in a configured TMS320F28335 DSP board and incorporating other associated accessories such as current sensors and incremental encoder. The comparative experiments evaluations are implemented while considering similar environments and conditions imposed during computer simulation.

The experimental results in constant torque and constant power regimes are evaluated in this section. Figures 7 and 8 display the experimental results of the transient performances considering the angular speed step change above and below rated values covering both regions, respectively. First, the IPMSM drive is operated up to near rated speed $2500 \mathrm{r} / \mathrm{min}$ (i.e. 1300 to $2450 \mathrm{r} / \mathrm{min}$ ). In this case, the maximum torque can readily be attained by invoking the maximum torque per ampere control. However, when the speed is varied stepwise from 1300 to $3000 \mathrm{r} / \mathrm{min}$ (i.e. operation from MTPA to beyond base speed) as uncovered by Figure 8 , the maximum electric torque can never be achieved anymore in this region and thus, flux weakening control (FWC) is recalled with enforced current and voltage constraints. This is due to the fact that the stator current trajectory defined by a pair of $i_{d s}$ and $i_{q s}$ that is generating the maximum electric torque can never be traced anymore beyond the base angular speed so as to sufficiently inscribe the maximum voltage boundaries. These descriptions have been illustratively depicted in Figure 1. From the smooth rotor angular speed and torque characteristic performances, it is quite apparent that the salient PMSM is sufficiently controlled using the direct DSPC scheme even in constant power region which is an attractive feature in EVs applications. 


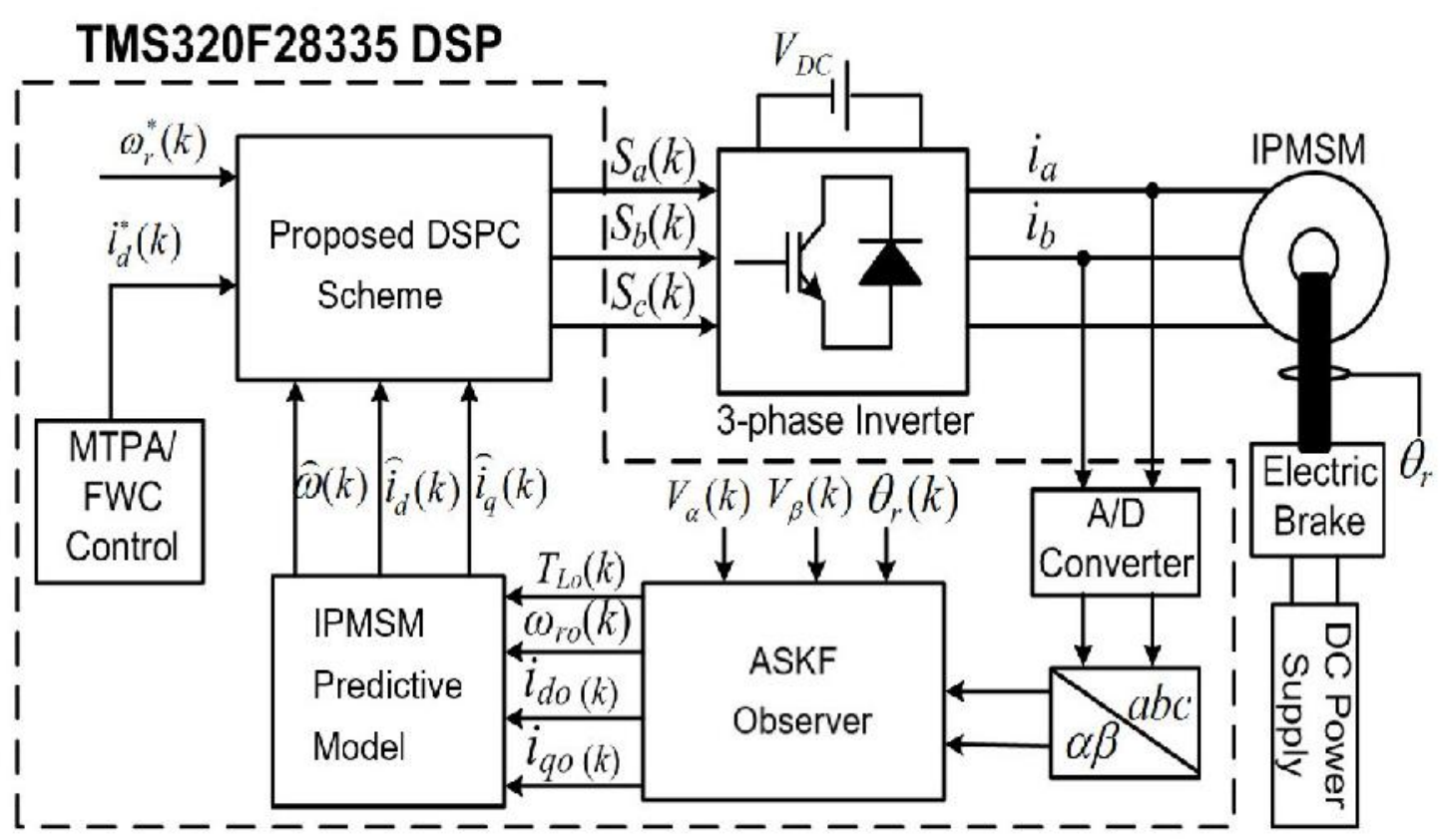

Figure 6: Laboratory salient PMSM prototype set up

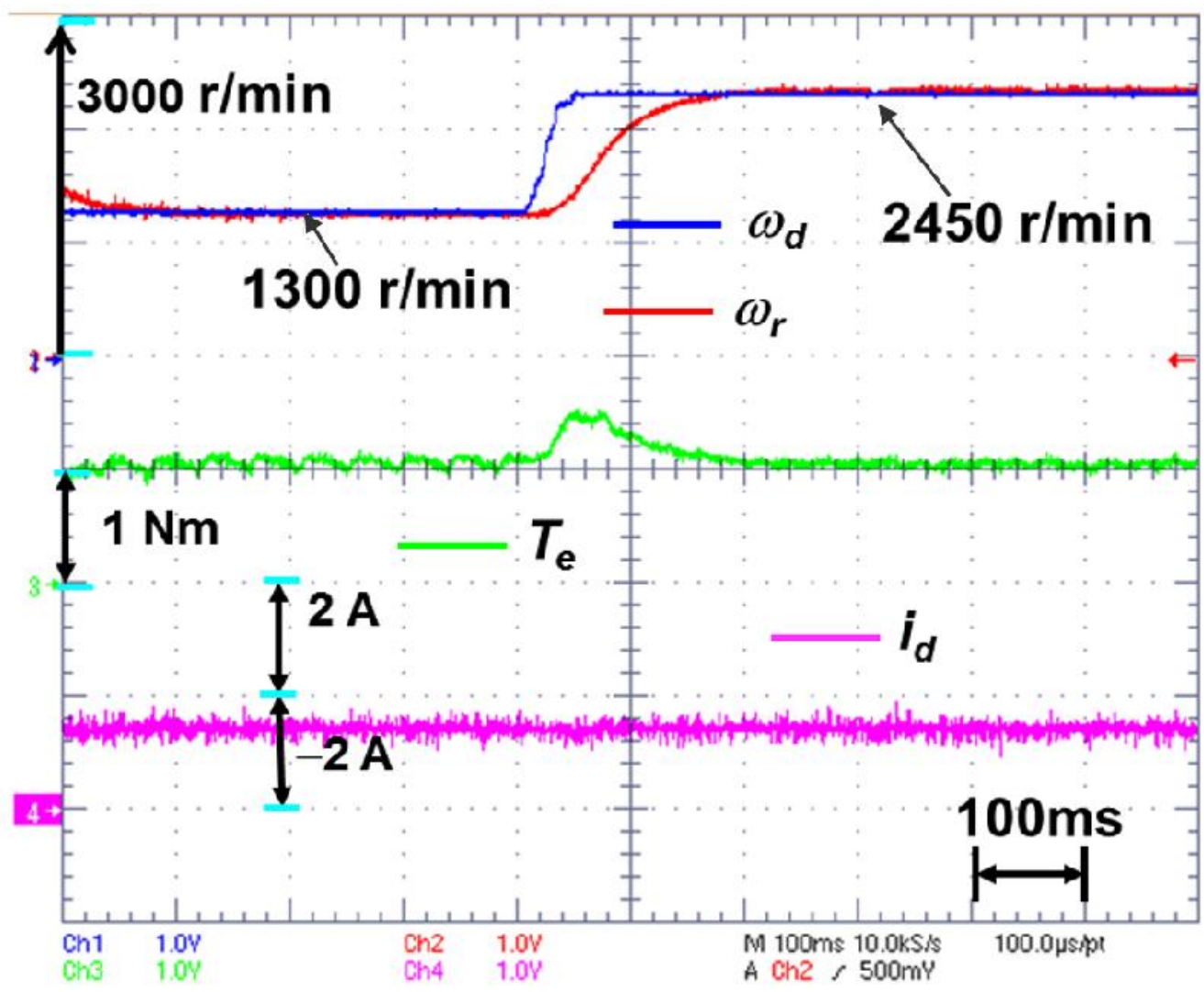

Figure 7: Experimental results of DSPC strategy in constant torque region using MTPA control 
Direct Predictive Speed Control of Salient PMSM Drives in Constant Torque and Constant Power Regimes for Electric Vehicles Applications

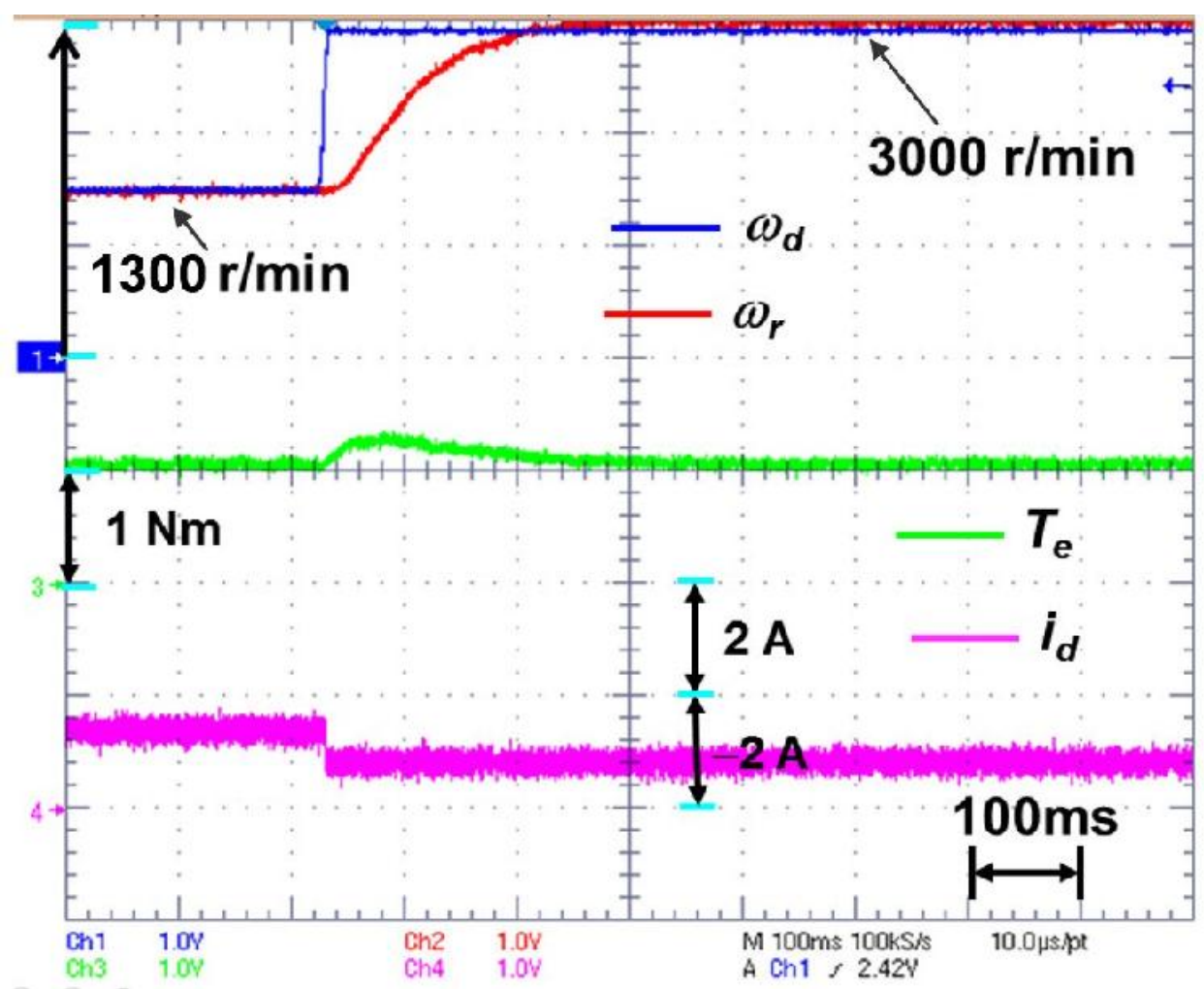

(a)

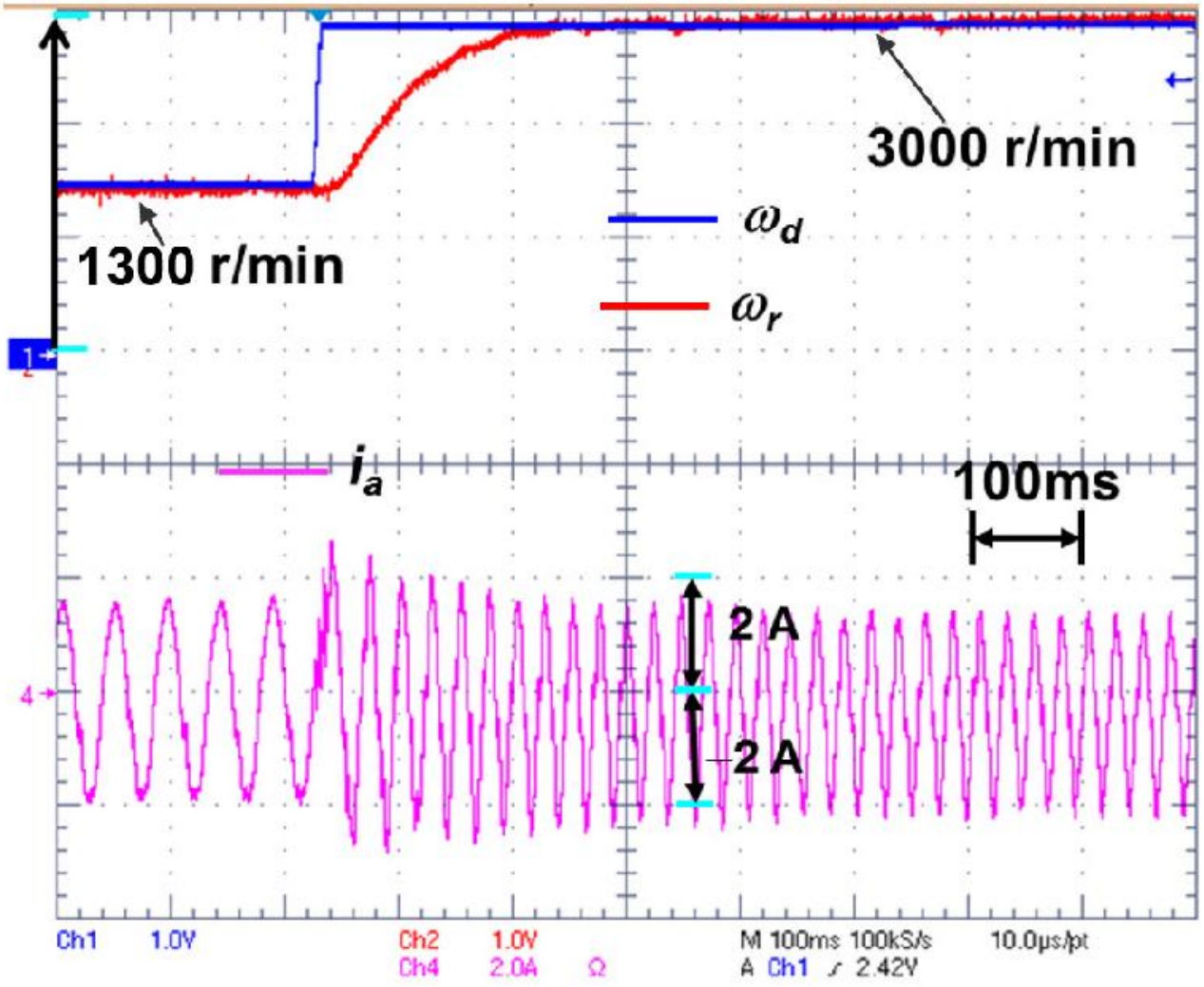

(b)

Figure 8: Experimental results of DSPC strategy the DSPC strategy in extended rotor angular speed 


\section{CONCLUSIONS}

A direct speed control strategy of salient PMSM drive inspired by model predictive control techniques for electric vehicle applications has been presented. The characteristic performances of the proposed DSPC strategy under several angular speed and torque dynamics have been extensively presented. The displayed results of the proposed strategy have demonstrated rapid dynamic responses and speedy recovery under abrupt unknown disturbances in comparison to the dual current control loop PI-based speed controller. The comparative performance evaluations have been confirmed by using the computer simulation performed using MATLAB/Simulink environment and the experimental results have been obtained via salient PMSM prototype equipped with TMS320F28335 DSP control board in constant torque and constant power regimes (i.e., flux weakening regions). Generally, the proposed DSPC strategy visibly demonstrated high-performance features like quicker transient response with excellent angular speed tracking capabilities. DSPC scheme with IPMSM validate promising results for electric vehicle applications, which require the drive performance cover extended angular speed range.

\section{REFERENCES}

Chan C. (2007). The State of the Art of Electric, Hybrid, and Fuel Cell Vehicles. IEEE Proceedings, 95(4): 704-718.

DOI:

10.1109/JPROC.2007.892489

Chan C.C., Chau K.T. and Jiang J.Z. (1996). Novel Permanent Magnet Motor Drives for Electric Vehicles. IEEE Transactions on Industrial Electronics, 43(2): 331-339.

Chau K.T. (2017). Electric Vehicle Machines and Drives: Design, Analysis and Application. Wiley. ISBN: 978-1118-75252-4
Choi H.H. and Jung J.W. (2012). Fuzzy speed control with an acceleration observer for a permanent magnet synchronous motor. Nonlinear Dynamics, 67: 1717-1727. DOI 10.1007/s11071-011-0099-y

Du G., Cao W., Hu S., Lin Z. and Yuan T. (2019). Design and Assessment of an Electric Vehicle Powertrain Model Based on Real-World Driving and Charging Cycles. İEEE Transactions on Vehicular Technology, 1178-1187. https://doi.org/10.1109/TVT.2018.2884 $\underline{812}$

Ehsani M., Rahman K.M. and Toliyat H. A. (1997). Propulsion System Design of Electric and Hybrid Vehicles. IEEE Transactions on Industrial Electronics. DOI: $10.1109 / 41.557495$

EV Specification (2020). Retrieved from https://www.evspecifications.com/en/m odel-acceleration/2d24e4

Fuentes E.J., Silva C.A. and Yuz J.I. (2012). Predictive speed control of a two-mass system driven by a permanent magnet synchronous motor. IEEE Transactions on Industrial Electronics, 57(7): 2840-2848. DOI:10.1109/TIE.2011.2158767

Geyer T. (2017). Model Predictive Control of High-Power Converters and Industrial Drives. Wiley. DOI: $10.1002 / 9781119010883$

Haessig D. and Friedland B. (1998). Separate-Bias Estimation with Reduced-Order Kalman Filters. IEEE Transactions on Automatic Control, 44(7): $983 \quad$ - 987. DOI: $10.1109 / 9.701106$

Huynh T.A. and Hsieh M.F. (2018). Performance Analysis of Permanent Magnet Motors for Electric Vehicles (EV) Traction Considering Driving Cycles,. Energies, 11(6): 1385. https://doi.org/10.3390/en11061385

Justo J.J. and Mwasilu F. (2019). Nonlinear Direct Torque Control of Interior Permanent Magnet Synchronous Motor Drive. Tanzania 
Journal of Engineering and Technology, 38(1): 15-26.

Justo J.J., Mwasilu F., Kim E.K., Kim J., Choi H.H. and Jung J.W. (2017). Fuzzy Model Predictive Direct Torque Control of IPMSMs for Electric Vehicle Applications. IEEE/ASME Transactions on Mechatronics, 40424045.

DOI: $10.1109 /$ TMECH.2017.2665670

Kang, S. W., Soh, J. H., \& Kim, R. Y. (2020). Symmetrical three-vectorbased model predictive control with deadbeat solution for IPMSM in rotating reference frame. IEEE Transactions on Industrial Electronics, 67(1): 159-168. https://doi.org/10.1109/TIE.2018.28904 90

Kim K.C. (2012). A Novel Magnetic Flux Weakening Method of Permanent Magnet Synchronous Motor for Electric Vehicles. IEEE Transactions on Magnetics, 48(11): 4042-4045. DOI: 10.1109/TMAG.2012.2198444

Kim K.H. and Youn M.J. (2002). A Nonlinear Speed Control for a PM Synchronous Motor using a Simple Disturbance Estimation Technique. IEEE Transactions on Industrial Electronics, 49(3): 524-535. DOI: $10.1109 /$ TIE.2002.1005377

Leu V.Q., Mwasilu F., Choi H.H., Lee J., and Jung J.W. (2014). Robust Fuzzy Neural Network Sliding Mode Control Scheme for IPMSM Drives. International Journal of Electronics, 919-938.

https://doi.org/10.1080/00207217.2013. 805359

Liu B., Zhao Y. and Hu H.Z. (2018). Structure-Variable Sliding Mode Control of Interior Permanent Magnet Synchronous Motor in Electric Vehicles with Improved Flux-Weakening Method. Advances in Mechanical Engineering, $10(1)$ : 1-12. https://doi.org/10.1177/1687814017704 $\underline{355}$
Liu J., Gong C., Han Z. and Yu H. (2018). IPMSM Model Predictive Control in Flux-weakening Operation Using an Improved Algorithm. IEEE Transactions on Industrial Electronics, 65(12): 9378-9387. DOI: $10.1109 /$ TIE.2018.2818640

Mynar Z., Vesely L. and Vaclavek P. (2016). PMSM Model Predictive Control with Field Weakening Implementation. IEEE Transactions on Industrial Electronics, 63(8): 5156 5166. doi: 10.1109/TIE.2016.2558165

Rajashekara K. (2013). Present Status and Future Trends in Electric Vehicle Propulsion Technologies. IEEE Journal of Emerging and Selected Topics in Power Electronics, 1(1): 3-10. DOI: 10.1109/JESTPE.2013.2259614

Rodriguez J. and Cortes P. (2012). Predictive Control of Power Converters and Electrical Drives. Wiley. ISBN: 978-1-119-96398-1

Santiago J.D. (2012). Electrical Motor Drivelines in Commercial All-Electric Vehicles: A Review. IEEE Transactions on Vehicular Technology, 61(2): 475484. DOI: $10.1109 /$ TVT.2011.2177873

Sul S.K. (2011). Control of Electric Machine Drive Systems. Wiley. 424 p., ISBN: 978-0-470-59079-9

Vukosavić S.N. (2007). Digital Control of Electrical Drives. Springer. ISBN 9780-387-48598-0

Wang L. (2009). Model Predictive Control System Design and Implementation Using MATLAB. Springer. 10.1007/978-184882-331-0

Wang L., Chai S., Yoo D., Gan L. and Ng K. (2015). PID and Predictive Control of Electrical Drives and Power Converters using MATLAB / Simulink. Wiley-IEEE Press. ISBN: 978-1-118-33944-2

Zhang Y., Cao W., McLoone S. and Morrow J. (2016). Design and Flux-Weakening Control of an Interior Permanent Magnet Synchronous Motor for Electric Vehicles. IEEE Transactions on Applied Superconductivity, 26(7): Article Sequence Number: 0606906, DOI: $\underline{\text { 10.1109/TASC. } 2016.2594863}$ 